\title{
Introducing a two-dimensional graph of docking score difference vs. similarity of ligand-receptor interactions
}

\author{
Mohammad Rizki Fadhil Pratama ${ }^{1}$, Hadi Poerwono ${ }^{2}$, Siswandono Siswodihardjo ${ }^{2,}$ \\ ${ }^{1}$ Doctoral Program of Pharmaceutical Science, Faculty of Pharmacy, Universitas Airlangga, Surabaya, East Java, Indonesia \\ ${ }^{2}$ Department of Pharmaceutical Chemistry, Faculty of Pharmacy, Universitas Airlangga, Surabaya, East Java, Indonesia \\ *Corresponding author: prof.sis@ff.unair.ac.id
}

SUBMITTED 18 December 2020 REVISED 27 January 2021 ACCEPTED 17 February 2021

\begin{abstract}
Observation of molecular docking results was generally performed by analyzing the docking score and the interacting amino acid residues separately either in tables or graphs. Sometimes it was not easy to rank the tested ligands' docking results, especially if there were many ligands. This study aims to introduce a new way to analyze docking results with a two-dimensional graph between the difference in docking score and the similarity of ligand-receptor interactions. Molecular docking was performed with one reference ligand and several test ligands. The docking score difference was obtained between the test and the reference ligands as the graph's x-axis. Meanwhile, the $y$-axis contains the similarity of ligand-receptor interactions, obtained from the ratio of amino acid residues and the types of interactions between the test and reference ligands. Docking result analysis was more straightforward because two critical parameters were presented in one graph. This graph could be used to support the analysis of the docking results.
\end{abstract}

KEYWORDS Analysis; docking; docking score; interaction; two-dimensional graph

\section{Introduction}

Molecular docking (or simply docking) is an in silico method used to analyze the interactions between two molecules. Of the two molecules, one will act as a test compound or ligand, while the other will act as a target or known as a receptor. In its use, the docking method is widely used in various purposes in the field of drug design and discovery, especially for screening in the discovery of potential compounds with certain potential activities, as well as to explain the mechanism of action of the interactions that occur between drug compounds with known activity against the target protein (Lin et al. 2020; Meng et al. 2012).

Compared to several other in silico methods, molecular docking is one of the most popular and widely used, both as the primary method and for confirming other methods. From the beginning of 2020 to October 2020 alone, there have been more than 10,000 articles from the Scopus database published with titles, keywords, or abstracts containing the keyword "molecular docking." This number is more than 1,000 articles compared to the previous year, confirming molecular docking's popularity. This is mainly due to molecular docking's various advantages, including a brief analysis process, low cost, and guaranteed safety because it does not use dangerous chemical reagents (Deshpande et al. 2020; Pinzi and Rastelli 2019).
Aside from its popularity, molecular docking also presents various challenges in its analysis. These obstacles are generally related to the type of software used, considering that much software can be used to perform molecular docking, both free and paid. Apart from the technical problems associated with the software used, one of the biggest challenges in analyzing the docking results is the ligand ranking based on the docking result (Pagadala et al. 2017).

Observations of molecular docking results are generally carried out by analyzing two main parameters of the docking results separately: the docking score and the interacting amino acid residues. These two parameters are equally important in the analysis of docking results. If the docking score is often associated with ligand affinity for the receptor, the ligand-receptor interaction becomes an indicator of whether the resulting interaction can cause activity or not, compared to reference/cocrystal ligands (Pantsar and Poso 2018; Ferreira et al. 2015). However, analyzing the two parameters simultaneously requires more effort, considering that one is quantitative while the other is qualitative (Vieira and Sousa 2019; Ramírez and Caballero 2016). This may not be a concern if only a few ligands are tested, but it will cause problems if the number of test ligands is large. The problem will arise when presenting the data, where there will be a very 
long table to present all the data.

An approach that can be taken to facilitate the analysis of the docking results' two parameters is to change the ligand-receptor interaction parameters into quantitative parameters so that the two parameters can be plotted as a graph with two parameters. The rational way is to compare the interacting amino acids and the types of interactions in the test ligands with those shown by the reference ligand, then expressed in terms of the percentage of similarity. This approach assumes that the more similar amino acid interactions will provide a greater chance of a similar mechanism of action, which will result in the same activity (Li et al. 2019; Ramírez and Caballero 2016). To the best of our knowledge, this approach has not been previously reported.

Based on this background, this study aims to introduce a new way to analyze docking results with a twodimensional graph between the difference in docking score and the similarity of ligand-receptor interactions.

\section{Materials and Methods}

For demonstration purposes, the docking process was performed using proteins that bind to the highly selective reference ligands, and the test ligands were compounds known to target these proteins. These reference ligands include a co-crystal ligand that binds to the receptor or compounds known to interact with the receptor's binding site (Kolb and Irwin 2009). The docking score and the ligand-receptor interactions will be used to compile a twodimensional graph between the difference in docking score and the similarity of ligand-receptor interactions.

The protein chosen was prostaglandin $\mathrm{G} / \mathrm{H}$ synthase 2 or cyclooxygenase 2 (COX-2), an enzyme as a target receptor with PDB ID 3LN1, which binds celecoxib, a selective COX-2 inhibitor. The receptor was chosen because of the availability of co-crystal ligand that were selective to the receptor, a high enough crystal resolution $(2.40 \AA)$ with 0 Ramachandran outliers (Wang et al. 2010), the results of redocking with low RMSD and $\Delta \mathrm{G}$ suggesting good binding affinity (Mandour et al. 2016), and has been reported to be used in docking studies more than 10 times in the past three years in the Scopus database. However, this approach was expected to be applied to other receptors as well.

\subsection{Materials}

\subsubsection{Ligands preparation}

As a representative of the test ligands, 15 antiinflammatory compounds were used either known to act on the COX-2 pathway (e.g., etoricoxib) or not (acetaminophen, aspirin). The test ligand structure was obtained from PubChem (https://pubchem.ncbi.nlm.nih.gov /) and then downloaded in SDF format. All test ligands were then prepared according to the method reported by Pratama et al. (2020) then saved in .pdbqt format.

\subsubsection{Receptor preparation}

The receptor used in the demonstration is COX-2, which binds to celecoxib (PDB ID 3LN1) and was downloaded from the Protein Data Bank website (https://www.rcsb.org ). The receptor consists of four chains (A, B, C, and D), with the chains used for the docking process was chain $\mathrm{A}$ (Wang et al. 2010). The parts of the receptors that were not used (e.g., water, solvent, unused chains) were then removed and given polar hydrogen as well as chargesand finally saved in .pdbqt format using AutoDockTools 1.5.6.

\subsection{Methods}

\subsubsection{Hardware and software}

The hardware and software used in this study were the same as the research reported by Pratama et al. (2020), with AutoDock Vina for docking and Discovery Studio Visualizer for visualization. Two-dimensional graphical creation of ligand-receptor interactions was carried out using Microsoft Excel 2019.

\subsubsection{Validation of docking protocol}

The docking protocol validation was carried out by the redocking method reported by Morris et al. (2009). The observed parameter was a root-mean-square deviation (RMSD). The RMSD value less than $2 \AA$ indicating a valid docking protocol and can be used for the docking process.

\subsubsection{Molecular docking}

Docking for all test ligands performed in the same way as the validation process with similar sizes and positions of the grid box. The results were grouped under two parameters: free energy of binding $(\Delta \mathrm{G}$; $\mathrm{kcal} / \mathrm{mol})$ and ligandreceptor interactions. The ligand-receptor interactions are recorded based on two parameters: the amino acids that interact and the types of interactions that occur. The docking process was repeated five times, and the average $\Delta \mathrm{G}$ value and the deviation were determined. The maximum allowable deviation value was $\pm 0.05 \mathrm{kcal} / \mathrm{mol}$ to avoid high variation. The two parameters were then compared their similarity to celecoxib as a reference ligand then the average was calculated and expressed as a percentage.

\subsubsection{Two-dimensional graph of ligand-receptor in- teractions}

The difference in $\Delta \mathrm{G}$ values and the ligand-receptor interactions obtained earlier was then used to create a two-dimensional graph. The $\mathrm{x}$-axis was filled with the reduction in the $\Delta \mathrm{G}$ value of each test ligand against the $\Delta \mathrm{G}$ value of the reference ligand (celecoxib). The difference from the $\Delta \mathrm{G}$ value of each test ligand against $\Delta \mathrm{G}$ celecoxib was calculated based on the following Equation 1: 


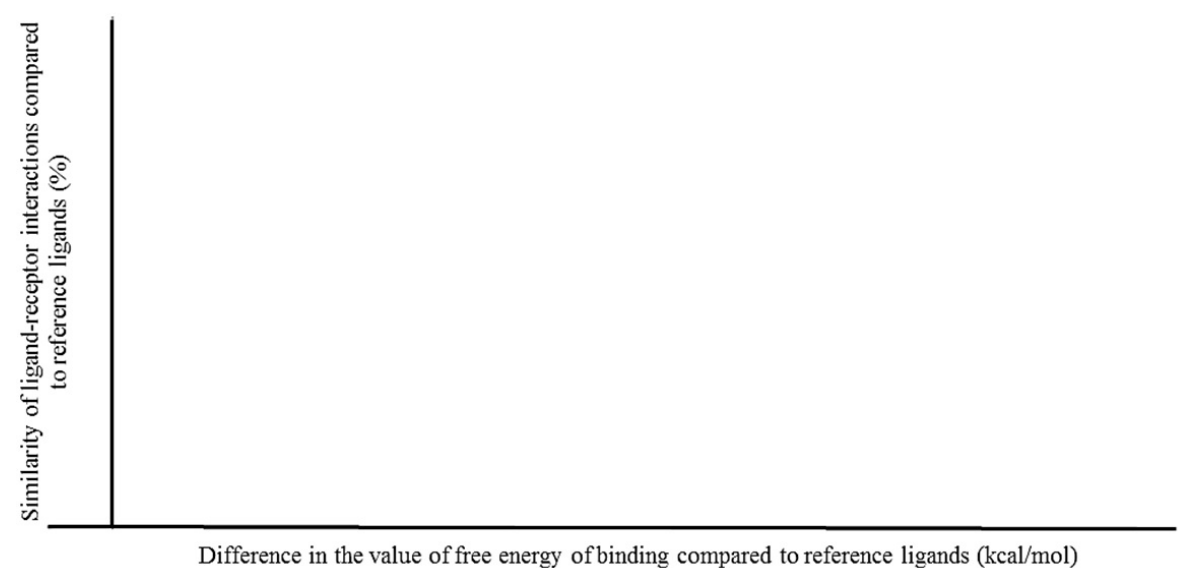

FIGURE 1 Two-dimensional graph outline. The further to the left and the higher the position of the test ligand, the better the ranking of the test ligand.

$$
\Delta G \text { dif }=\Delta \text { Gtest }-\Delta \text { Gref }
$$

$\Delta \mathrm{Gdif}=$ the difference from the $\Delta \mathrm{G}$ of test and reference ligand $\Delta \mathrm{Gtest}=\Delta \mathrm{G}$ of test ligand

$\Delta \mathrm{Gref}=\Delta \mathrm{G}$ of reference ligand

The higher the difference in value, the lower the potential for affinity than the reference ligand, and vice versa. If the difference value is negative, it indicates that the test ligand has a higher potential for affinity than the reference ligand.

Meanwhile, the y-axis is filled with the average percentage of the similarity of the amino acids that interact and the types of interactions. The similarity of the interacting amino acids was calculated by dividing the number of amino acids interacting with both the test and the reference ligand, divided by the total amino acids interacting with the reference ligand. Meanwhile, the similarity of interaction types is calculated by dividing the number of amino acids with the same types of interactions for both the test ligand and the reference ligand, divided by the number of amino acid interactions on the reference ligand. The two parameters were then averaged and expressed as a percentage as shown in the following Equation 2:

$$
\% \text { similarity }=\left(\left(0.5 \times\left(\frac{n \text { AAtest }}{n \text { AAref }}\right)\right)+\left(0.5 \times\left(\frac{\text { intAAtest }}{\text { intAAref }}\right)\right)\right) \times 100 \%
$$

$\%$ similarity = similarity of ligand-receptor interaction

nAAtest $=$ the number of amino acids of the test ligand that also interacts with the reference ligand

nAAref $=$ the number of amino acids of the reference ligand

intAAtest $=$ the number of amino acid interactions of the test ligand that is also present in the reference ligand

intAAref = the number of amino acid interactions of the reference ligand

The number 0.5 in the ligand-receptor interaction similarity equation shows the impact of each parameter on the similarity of the ligand-receptor interaction. At the time of writing, it was still unknown how the influence of the amino acids that interact and the types of interactions that occur on ligand-receptor interactions. The initial assumption used was that the two parameters had the same effect on the ligand-receptor interaction, so the impact weight given was the same. This opens up opportunities for further research regarding the comparison of the effects of the two on ligand-receptor interactions. The two parameters were then used to quantitatively express the similarity of the ligand-receptor interactions on the y-axis, as shown in Figure 1.

\section{Results and Discussion}

\subsection{Validation of docking protocol}

The RMSD value of the redocking process obtained was $0.857 \AA$, indicating that the docking protocol was valid. The visualization of ligand overlays from redocking with reference ligand from crystallographic results was presented in Figure 2. The redocking ligands' appearance shows the same orientation as the crystallographic ligands, apart from a slight shifted in position. The results of the

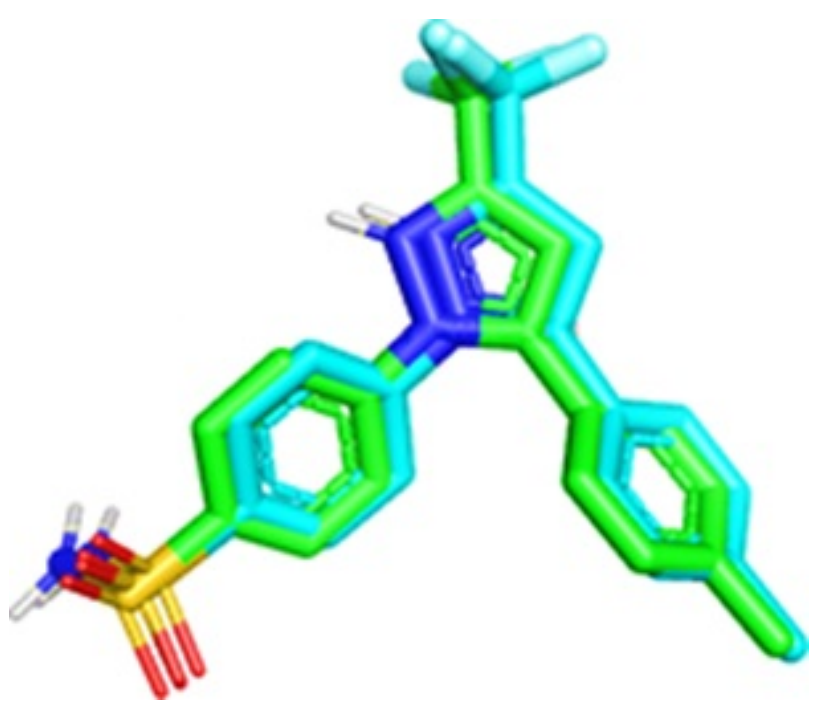

FIGURE 2 Overlays of redocking ligands (blue) with reference ligands from crystallography data (green) at receptors 3LN1 with RMSD $0.857 \AA$ 


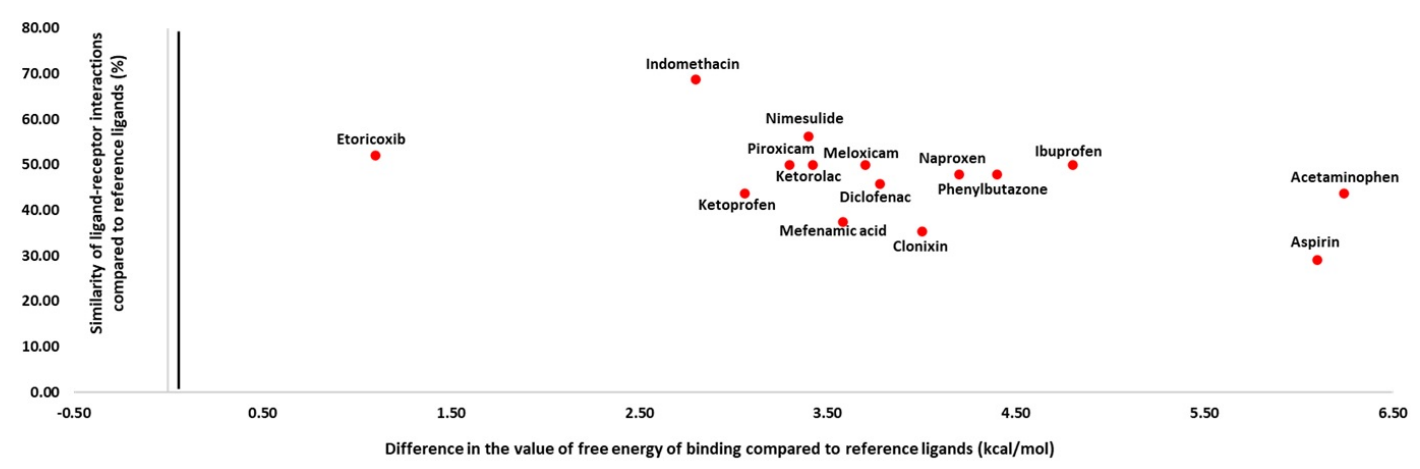

FIGURE 3 Two-dimensional graph between the difference in the value of free energy of binding and the percentage of similarity of ligandreceptor interactions compared to reference ligand on the 3LN1 receptor. The test ligands with the best docking results are etoricoxib (far left) and indomethacin (topmost).

TABLE 1 Docking protocol and process validation results.

\begin{tabular}{|c|c|}
\hline Parameters & Values \\
\hline PDB ID & 3LN1 \\
\hline Reference ligand & Celecoxib \\
\hline Grid box size $(\AA ̊)$ & $32 \times 20 \times 26$ \\
\hline \multirow[t]{3}{*}{ Grid box position } & $x: 30.092$ \\
\hline & $y:-22.559$ \\
\hline & z: -15.758 \\
\hline $\operatorname{RMSD}(\AA ̊)$ & 0.857 \\
\hline$\Delta \mathrm{G} \pm \mathrm{SD}(\mathrm{kcal} / \mathrm{mol})$ & $-12.5 \pm 0$ \\
\hline \multirow[t]{24}{*}{ Amino acid residues } & $75-\mathrm{His}^{\mathrm{a}}$ \\
\hline & $102-\mathrm{Val}^{\mathrm{b}}$ \\
\hline & 106-Argb \\
\hline & $178-G \ln ^{a}$ \\
\hline & $335-\mathrm{Val}^{\mathrm{c}}$ \\
\hline & 338-Leua \\
\hline & 339-Ser ${ }^{\mathrm{a}}$ \\
\hline & 340-Glyb \\
\hline & $341-\mathrm{Tyr}^{\mathrm{b}}$ \\
\hline & 345-Leu ${ }^{b}$ \\
\hline & 367-Phe ${ }^{b}$ \\
\hline & 370-Leu ${ }^{d}$ \\
\hline & 371-Tyr ${ }^{d}$ \\
\hline & 373-Trp ${ }^{d}$ \\
\hline & 499-Arga \\
\hline & 502-Alab \\
\hline & $503-11 e^{b}$ \\
\hline & 504-Phe ${ }^{a}$ \\
\hline & 508-Met ${ }^{\mathrm{b}}$ \\
\hline & $509-\mathrm{Val}^{\mathrm{C}}$ \\
\hline & 512-Glye \\
\hline & 513-Ala ${ }^{d}$ \\
\hline & $516-\operatorname{Ser}^{\mathrm{b}}$ \\
\hline & 517-_eub \\
\hline
\end{tabular}

aHydrogen bonds; bVan der Waals interaction; cPi-sigma; ${ }^{d}$ Alkyl/Pi-alkyl; ePi-Pi T-shaped/Pi-Pi stacked/Amide-Pi stacked validation, along with the docking protocol used, were presented in Table 1. The dimensions of the grid box used were relatively small with a size of $32 \times 20 \times 26 \AA$, adjusting to the size of the reference ligands, which are also small. The redocking results showed that 24 amino acids interacted with celecoxib. The interactions were dominated by weak interactions such as Van der Waals (11 amino acids) but had considerably strong interactions such as hydrogen bonds (six amino acids).

\subsection{Molecular docking}

Docking of all test ligands shows the results as predicted, in which the ligands that were known to target $\mathrm{COX}-2$, such as etoricoxib, had the lowest AG value of $-11.4 \pm 0$ $\mathrm{kcal} / \mathrm{mol}$. This value is only a $1.1 \mathrm{kcal} / \mathrm{mol}$ difference from that shown by the celecoxib from the redocking process which is $-12.5 \pm 0 \mathrm{kcal} / \mathrm{mol}$, while the other test ligands show a difference between 2.8 to $6.24 \mathrm{kcal} / \mathrm{mol}$. Etoricoxib also had a high similarity of interacting amino acid residues with $79.17 \%$, but interaction type was lowered with $25 \%$. The average of both was $52.08 \%$, still lowered than some other test ligands such as indomethacin and nimesulide, with $68.75 \%$ and $56.25 \%$, respectively. Apart from having the highest similarity, indomethacin also had the second-lowest docking value after etoricoxib with -9.7 $\pm 0 \mathrm{kcal} / \mathrm{mol}$, making both etoricoxib and indomethacin the two test ligands with the closest parameter of celecoxib as reference ligands. In other words, these two ligands were the strongest candidates compared to other test ligands. The docking of all test ligands at the binding site of the 3LN1 receptor was presented in Table 2 and then used to filled in the two-dimensional graph plotted previously, as presented in Figure 3.

\subsection{Discussion}

The docking results were consistent with other studies reported previously by Sadasivam et al. (2020), in which a ligand such as etoricoxib, designed as a selective COX-2 inhibitor, show the highest potency compares to other ligands. The docking results also show that indomethacin has potential, although it is not a selective COX-2 inhibitor. These results are consistent with research from Abuelizz 
et al. (2017) and Oniga et al. (2017), who reported indomethacin's potency against COX-2. The 3LN1 receptor selection itself was based on the consistency of results from several previous studies (Coy-barrera 2020; Molinari et al. 2019; Shrivastava et al. 2017). In other words, the docking results obtained for the demonstration are appropriate and in line with other studies. However, there are more interesting points to discuss.

As mentioned in the previous section, the more the number of test ligands will cause more data to be presented. However, by presenting the docking result data in a two-dimensional graph, the data presented is much more concise while still presenting essential data for analysis. Readers do not have to read the entire docking results table to find the ligands with the best docking results. Otherwise, they only need to look for the test ligand located on the upper left of the graph to determine which test ligand has the smallest difference in docking values and the highest ligand-receptor interaction similarity with the reference ligand. This also makes the presentation of the results shorter even though the number of ligands tested is immense, considering that the graph space remains the same and does not depend on the number of test ligands.

There are times when the ligands with the smallest docking score difference and the highest ligand-receptor interaction similarity compared to reference ligands are two different test ligands, as presented in the results of this study (etoricoxib and indomethacin). In that case, the recommendations that can be given for both, considering these two parameters are equally crucial in molecular docking. It has been occasionally reported that the test ligand with the best docking score has an unstable interaction with the receptor when tested by molecular dynamics, compared to the test ligand with a ligand-receptor interaction closer to the ligand reference (Lam et al. 2018; Salmaso and Moro 2018).

One of the essential points in presenting the docking results in this two-dimensional graph is the obligation to provide reference ligands for comparison, considering that some of the receptors available in the protein data bank are apo-receptors (Forli et al. 2016). For new target receptors for which no proven reference ligands have been found, it is not possible to present the docking results in a twodimensional graph. Under these conditions, it is highly recommended to conduct in vitro and in vivo studies first to ensure that the reference ligand to be used is proven.

This two-dimensional graph has been used before to present the docking results of several types of receptors (Pratama et al. 2020, 2021). Research by Pratama et al. (2020) even presents the docking results of two receptors

TABLE 2 Results of the docking of all test ligands at the binding site of the 3LN1 receptor.

\begin{tabular}{|c|c|c|c|c|c|c|c|c|c|c|c|c|c|c|c|}
\hline Ligand & Act & Asp & $\mathrm{Cln}$ & $\mathrm{Dcl}$ & Etr & Ibp & Ind & Ktp & Ktr & Mfn & Mlx & $\mathrm{Npr}$ & Nms & $\mathrm{Phn}$ & Prx \\
\hline$\Delta \mathrm{G} \pm \mathrm{SD}(\mathrm{kcal} / \mathrm{mol})$ & $-6.26 \pm 0.05$ & $-6.4 \pm 0$ & $-8.5 \pm 0$ & $-8.72 \pm 0.04$ & $-11.4 \pm 0$ & $-7.7 \pm 0$ & $-9.7 \pm 0$ & $-9.44 \pm 0.05$ & $-9.08 \pm 0.04$ & $-8.92 \pm 0.04$ & $-8.8 \pm 0$ & $-8.3 \pm 0$ & $-9.1 \pm 0$ & $-8.1 \pm 0$ & $-9.2 \pm 0$ \\
\hline \multirow[t]{25}{*}{ Amino acid residues } & $75-\mathrm{His}^{\mathrm{a}}$ & - & $75-\mathrm{His}^{f}$ & - & $75-\mathrm{His}^{\mathrm{a}}$ & $75-\mathrm{His}^{\mathrm{a}}$ & $75-\mathrm{His}^{\mathrm{a}}$ & $75-\mathrm{His}^{\mathrm{a}}$ & $75-\mathrm{His}^{\mathrm{a}}$ & $75-\mathrm{His}^{f}$ & $75-\mathrm{His}^{f}$ & $75-\mathrm{His}^{\mathrm{b}}$ & $75-\mathrm{His}^{\mathrm{b}}$ & & $75-\mathrm{His}^{\mathrm{f}}$ \\
\hline & - & - & - & - & - & - & $102-\mathrm{Val}^{\mathrm{a}}$ & - & - & - & - & - & - & - & - \\
\hline & - & - & - & 106-Arg ${ }^{\mathrm{b}}$ & - & - & 106- $-\operatorname{Arg}^{\mathrm{a}}$ & - & - & - & - & - & 106-Arg ${ }^{\mathrm{b}}$ & 106-Arg ${ }^{\mathrm{a}}$ & - \\
\hline & $178-\mathrm{Gln}^{\mathrm{a}}$ & - & - & - & $178-\mathrm{Gln}^{\mathrm{a}}$ & - & - & $178-\mathrm{Gln}^{\mathrm{a}}$ & - & - & - & - & - & - & - \\
\hline & - & 334-Tyr ${ }^{\mathrm{a}}$ & 334-Tyr ${ }^{\mathrm{a}}$ & - & - & 334-Tyr ${ }^{f}$ & - & - & 334-Tyr ${ }^{\mathrm{a}}$ & 334-Tyr ${ }^{\mathrm{a}}$ & - & 334-Tyr ${ }^{\mathrm{a}}$ & - & - & - \\
\hline & $335-\mathrm{Val}^{\mathrm{a}}$ & $335-\mathrm{Val}^{\mathrm{a}}$ & $335-\mathrm{Val}^{f}$ & $335-\mathrm{Val}^{\mathrm{f}}$ & $335-\mathrm{Val}^{\mathrm{f}}$ & $335-\mathrm{Val}^{\mathrm{f}}$ & $335-\mathrm{Val}^{\mathrm{f}}$ & $335-\mathrm{Val}^{\mathrm{a}}$ & $335-\mathrm{Val}^{\mathrm{f}}$ & $335-\mathrm{Val}^{f}$ & $335-\mathrm{Val}^{\mathrm{a}}$ & $335-\mathrm{Val}^{\mathrm{a}}$ & $335-\mathrm{Val}^{\mathrm{a}}$ & $335-\mathrm{Val}^{f}$ & $335-\mathrm{Val}^{\mathrm{a}}$ \\
\hline & 338-Leu ${ }^{\mathrm{b}}$ & 338-Leu ${ }^{\mathrm{a}}$ & 338-Leuf & 338-Leu ${ }^{a}$ & 338-Leu ${ }^{\mathrm{a}}$ & 338-Leu ${ }^{f}$ & 338-Leu ${ }^{f}$ & 338-Leuf ${ }^{f}$ & 338-Leu ${ }^{\mathrm{C}}$ & 338-Leuf ${ }^{f}$ & 338-Leu ${ }^{\mathrm{a}}$ & 338-Leuf ${ }^{f}$ & 338-Leuf ${ }^{f}$ & 338-Leuf ${ }^{f}$ & 338-Leu ${ }^{\mathrm{a}}$ \\
\hline & $339-\mathrm{Ser}^{\mathrm{b}}$ & $339-\mathrm{Ser}^{\mathrm{a}}$ & $339-\operatorname{Ser}^{\mathrm{a}}$ & $339-\mathrm{Ser}^{\mathrm{a}}$ & $339-\mathrm{Ser}^{\mathrm{C}}$ & $339-\mathrm{Ser}^{\mathrm{a}}$ & $339-\operatorname{Ser}^{\mathrm{a}}$ & $339-\operatorname{Ser}^{\mathrm{C}}$ & $339-\operatorname{Ser}^{\mathrm{C}}$ & $339-\operatorname{Ser}^{\mathrm{a}}$ & $339-\operatorname{Ser}^{\mathrm{C}}$ & $339-\operatorname{Ser}^{\mathrm{C}}$ & $339-$ Ser $^{b}$ & $339-$ Ser $^{\mathrm{a}}$ & $339-\operatorname{Ser}^{\mathrm{a}}$ \\
\hline & $340-G l y^{a}$ & - & - & - & - & - & - & - & - & - & - & - & - & - & - \\
\hline & $341-\mathrm{Tyr}^{\mathrm{a}}$ & - & $341-\mathrm{Tyr}^{\mathrm{f}}$ & $341-\mathrm{Tyr}^{\mathrm{b}}$ & 341-Tyr ${ }^{f}$ & 341-Tyr ${ }^{b}$ & 341-Tyr ${ }^{\mathrm{a}}$ & $341-\mathrm{Tyr}^{\mathrm{a}}$ & 341-Tyr ${ }^{\mathrm{a}}$ & 341-Tyr ${ }^{f}$ & $341-\mathrm{Tyr}^{\mathrm{a}}$ & $341-\mathrm{Tyr}^{\mathrm{a}}$ & 341-Tyr ${ }^{\mathrm{a}}$ & 341-Tyr ${ }^{\mathrm{a}}$ & 341-Tyr ${ }^{\mathrm{a}}$ \\
\hline & - & - & - & - & 345-Leu ${ }^{f}$ & - & 345-Leu ${ }^{\mathrm{a}}$ & - & - & - & - & - & - & - & - \\
\hline & - & 367-Phe ${ }^{\mathrm{a}}$ & 367-Phe ${ }^{\mathrm{a}}$ & $367-\mathrm{Phe}^{\mathrm{a}}$ & - & 367-Phe ${ }^{\mathrm{a}}$ & 367-Phe ${ }^{f}$ & - & 367-Phe ${ }^{a}$ & 367-Phe ${ }^{\mathrm{a}}$ & 367-Phe ${ }^{\mathrm{a}}$ & $367-\mathrm{Phe}^{\mathrm{a}}$ & - & 367-Phe ${ }^{\mathrm{a}}$ & 367-Phe ${ }^{\mathrm{a}}$ \\
\hline & - & 370-Leu ${ }^{\mathrm{a}}$ & 370-Leu ${ }^{\mathrm{a}}$ & 370-Leu ${ }^{\mathrm{a}}$ & 370-Leu ${ }^{\mathrm{a}}$ & 370-Leu ${ }^{\mathrm{a}}$ & 370-Leu ${ }^{f}$ & - & 370-Leu ${ }^{\mathrm{a}}$ & 370-Leu ${ }^{\mathrm{a}}$ & 370-Leu ${ }^{\mathrm{a}}$ & - & 370-Leu ${ }^{a}$ & 370-Leuf ${ }^{f}$ & 370-Leu ${ }^{\mathrm{a}}$ \\
\hline & - & 371-Tyr b & $371-\mathrm{Tyr}^{\mathrm{a}}$ & 371-Tyr ${ }^{\mathrm{a}}$ & - & 371-Tyr ${ }^{f}$ & 371-Tyr & - & 371-Tyrb & 371-Tyrb & 371-Tyra & $371-\mathrm{Tyr}^{\mathrm{a}}$ & - & 371-Tyr ${ }^{f}$ & 371-Tyra \\
\hline & - & 373-Trp ${ }^{\mathrm{d}}$ & 373-Trp ${ }^{a}$ & 373-Trp ${ }^{a}$ & 373-Trpa & 373-Trp ${ }^{f}$ & 373-Trpd & 373-Trp ${ }^{a}$ & 373-Trp ${ }^{a}$ & 373-Trp ${ }^{d}$ & 373-Trpa & - & 373-Trp ${ }^{a}$ & 373-Trp ${ }^{f}$ & 373-Trpa \\
\hline & 499-Arg b & - & - & - & 499-Arg b & 499-Arg ${ }^{b}$ & 499-Arga & 499-Arg ${ }^{b}$ & 499-Arg ${ }^{a}$ & - & 499-Arga & 499- $\mathrm{Arg}^{\mathrm{a}}$ & 499- $\operatorname{Arg}^{\mathrm{a}}$ & - & 499-Arg ${ }^{a}$ \\
\hline & 502-Ala ${ }^{\mathrm{a}}$ & - & - & - & $502-\mathrm{Ala}^{\mathrm{a}}$ & $502-\mathrm{Al}^{\mathrm{a}}$ & 502-Ala $a^{a}$ & 502-Ala ${ }^{\mathrm{a}}$ & $502-\mathrm{Ala}^{\mathrm{a}}$ & - & 502-Ala ${ }^{f}$ & $502-\mathrm{Ala}^{\mathrm{a}}$ & 502-Ala ${ }^{a}$ & - & 502-Ala ${ }^{\mathrm{a}}$ \\
\hline & $503-11 e^{a}$ & - & - & - & $503-11 e^{a}$ & $503-11 e^{a}$ & - & $503-11 e^{a}$ & $503-11 e^{a}$ & - & - & - & $503-11 e^{a}$ & - & $503-11 e^{a}$ \\
\hline & 504-Phe ${ }^{a}$ & 504-Phe ${ }^{a}$ & 504-Phe ${ }^{f}$ & 504-Phe ${ }^{f}$ & 504-Phe & 504-Phe ${ }^{a}$ & 504-Phe ${ }^{a}$ & 504-Phe ${ }^{\mathrm{b}}$ & 504-Phe ${ }^{f}$ & 504-Phe ${ }^{f}$ & 504-Phe ${ }^{\mathrm{e}}$ & 504-Phe ${ }^{\mathrm{a}}$ & 504-Phe ${ }^{d}$ & 504-Phe ${ }^{f}$ & 504-Phe ${ }^{a}$ \\
\hline & - & 508-Met ${ }^{\mathrm{e}}$ & 508-Met ${ }^{\mathrm{b}}$ & 508-Met ${ }^{\mathrm{f}}$ & $508-\mathrm{Met}^{\mathrm{b}}$ & - & 508-Met ${ }^{\mathrm{a}}$ & 508-Met ${ }^{\mathrm{a}}$ & 508-Met ${ }^{\mathrm{a}}$ & 508-Met ${ }^{\mathrm{e}}$ & 508-Met ${ }^{\mathrm{a}}$ & - & 508-Met ${ }^{\mathrm{a}}$ & 508-Met ${ }^{f}$ & 508-Met ${ }^{\mathrm{a}}$ \\
\hline & $509-\mathrm{Val}^{\mathrm{C}}$ & $509-\mathrm{Val}^{\mathrm{a}}$ & $509-\mathrm{Val}^{f}$ & $509-\mathrm{Val}^{\mathrm{C}}$ & $509-\mathrm{Val}^{\mathrm{C}}$ & $509-\mathrm{Val}^{\mathrm{f}}$ & $509-\mathrm{Val}^{\mathrm{C}}$ & $509-\mathrm{Val}^{\mathrm{C}}$ & $509-\mathrm{Val}^{\mathrm{C}}$ & $509-\mathrm{Val}^{\mathrm{C}}$ & $509-\mathrm{Val}^{\mathrm{C}}$ & $509-\mathrm{Val}^{\mathrm{C}}$ & $509-\mathrm{Val}^{\mathrm{C}}$ & $509-\mathrm{Val}^{\mathrm{C}}$ & $509-\mathrm{Val}^{\mathrm{f}}$ \\
\hline & - & $512-G^{a}{ }^{a}$ & 512-Gly & $512-$ Gly $^{d}$ & $512-\mathrm{Gly}^{\mathrm{a}}$ & $512-\mathrm{Gly}^{\mathrm{a}}$ & 512-Gly ${ }^{a}$ & $512-\mathrm{Gly}^{\mathrm{a}}$ & $512-\mathrm{Gly}^{\mathrm{a}}$ & $512-\mathrm{Gly}^{\mathrm{a}}$ & $512-$ Gly $^{d}$ & 512-Gly ${ }^{\mathrm{a}}$ & $512-$ Gly $^{\mathrm{a}}$ & $512-$ Gly $^{\mathrm{a}}$ & $512-\mathrm{Gly}^{\mathrm{d}}$ \\
\hline & 513-Ala ${ }^{\mathrm{a}}$ & 513-Ala ${ }^{\mathrm{a}}$ & 513-Ala ${ }^{f}$ & 513-Ala ${ }^{f}$ & 513-Ala ${ }^{a}$ & 513-Ala ${ }^{a}$ & 513-Ala ${ }^{f}$ & - & $513-\mathrm{Ala}^{\mathrm{a}}$ & 513-Ala ${ }^{f}$ & 513-Ala ${ }^{\mathrm{a}}$ & 513-Ala ${ }^{f}$ & 513-Ala ${ }^{a}$ & 513-Ala ${ }^{C}$ & 513-Ala ${ }^{\mathrm{a}}$ \\
\hline & - & $516-\operatorname{Ser}^{\mathrm{b}}$ & $516-\operatorname{Ser}^{b}$ & $516-\operatorname{Ser}^{\mathrm{a}}$ & $516-\operatorname{Ser}^{\mathrm{a}}$ & $516-\mathrm{Ser}^{\mathrm{a}}$ & $516-\mathrm{Ser}^{\mathrm{a}}$ & - & $516-\operatorname{Ser}^{\mathrm{b}}$ & $516-\operatorname{Ser}^{b}$ & $516-\mathrm{Ser}^{\mathrm{b}}$ & $516-\mathrm{Ser}^{\mathrm{a}}$ & & 516-Ser ${ }^{b}$ & $516-\operatorname{Ser}^{b}$ \\
\hline & - & - & - & 517-Leu ${ }^{\mathrm{a}}$ & 517-Leua & - & 517-Leu ${ }^{a}$ & - & - & - & 517-Leu ${ }^{\mathrm{a}}$ & 517-Leu ${ }^{\mathrm{a}}$ & 517-Leu ${ }^{\mathrm{a}}$ & 517-Leuf ${ }^{f}$ & - \\
\hline The similarity of & \multirow{5}{*}{54.17} & \multirow{5}{*}{54.17} & \multirow{5}{*}{62.5} & \multirow{5}{*}{66.67} & \multirow{5}{*}{79.17} & \multirow{5}{*}{70.83} & \multirow{5}{*}{87.5} & \multirow{5}{*}{58.33} & \multirow{5}{*}{75} & \multirow{5}{*}{62.5} & \multirow{5}{*}{75} & \multirow{5}{*}{62.5} & \multirow{5}{*}{75} & \multirow{5}{*}{66.67} & \multirow{5}{*}{75} \\
\hline amino acids with & & & & & & & & & & & & & & & \\
\hline reference ligand & & & & & & & & & & & & & & & \\
\hline (\%) & & & & & & & & & & & & & & & \\
\hline The similarity & & & & & & & & & & & & & & & \\
\hline in the type of & \multirow[t]{4}{*}{33.33} & \multirow{4}{*}{4.17} & \multirow{4}{*}{8.33} & \multirow{4}{*}{25} & \multirow[t]{4}{*}{25} & \multirow[t]{4}{*}{29.17} & 50 & 29.17 & 25 & 12.5 & 25 & 33.33 & 37.5 & 29.17 & 25 \\
\hline interaction with & & & & & & & & & & & & & & & \\
\hline reference ligand & & & & & & & & & & & & & & & \\
\hline (\%) & & & & & & & & & & & & & & & \\
\hline The similarity of & 43.75 & 29.17 & 35.42 & 45.83 & 52.08 & 50 & 68.75 & 43.75 & 50 & 37.5 & 50 & 47.92 & 56.25 & 47.92 & 50 \\
\hline ligand-receptor & & & & & & & & & & & & & & & \\
\hline interaction* (\%) & & & & & & & & & & & & & & & \\
\hline
\end{tabular}


in one graph simultaneously by providing different color dots, showing the advantage that this two-dimensional graph can be used to present the docking results of multiple receptors at once. This is advantageous because it can streamline research reports, considering that some studies with molecular docking are carried out at more than one receptor, while some scientific journals impose limits on the number of supporting illustrations such as tables and figures in the manuscript. Thus, it is expected that the presentation of docking results in this two-dimensional graph can become a new trend in the presentation of docking results.

Apart from its simplicity, two things can still be improved in the presentation with these two-dimensional graphics. First, given that some of the test ligands can have very similar docking scores and ligand-receptor interactions often due to similar structures (Gimeno et al. 2019), it is possible that some ligands are very close together and even overlap on the graph. An enlarged version of the graph is required to overcome the above mentioned in the area where the ligands overlap. Second, as previously described, the calculation between the similarity of the interacting amino acids and the types of interactions averaged is assumed to have the same impact. Meanwhile, no previous research has proven and calculated these two parameters' impact on the docking results. Hence, there is an opportunity for further research on how to compare the impact of the two parameters on docking results, whether they have the same impact or whether one has more impact than the other.

\section{Conclusions}

The two-dimensional graph between the difference in docking score and the similarity of ligand-receptor interactions can support the analysis of the docking results by presenting the docking results briefly.

\section{Acknowledgments}

This research did not get funding from any external parties. The authors are grateful to the Faculty of Pharmacy, Universitas Airlangga, for facilitating the implementation of this research.

\section{Authors' contributions}

MRFP, HP, SS conceptualization. MRFP data curation. MRFP, SS formal analysis. HP, SS funding acquisition. MRFP, SS investigation. MRFP, SS methodology. HP, SS project administration. HP, SS resources. SS software. HP, SS supervision. MRFP validation. MRFP visualization. MRFP writing - original draft. HP, SS writing review \& editing. All authors read and approved the final version of the manuscript.

\section{Competing interests}

The author declare that they have no competing interest.

\section{References}

Abuelizz HA, Al-Salahi R, Al-Asri J, Mortier J, Marzouk M, Ezzeldin E, Ali AA, Khalil MG, Wolber G, Ghabbour HA, Almehizia AA, Abdel Jaleel GA. 2017. Synthesis, crystallographic characterization, molecular docking and biological activity of isoquinoline derivatives. Chem Cent J. 11(1):103. doi:10.1186/s13065-017-0321-1.

Coy-barrera E. 2020. Discrimination of naturallyoccurring 2-arylbenzofurans as cyclooxygenase-2 inhibitors: Insights into the binding mode and enzymatic inhibitory activity. Biomolecules. 10(2):176. doi:10.3390/biom10020176.

Deshpande RR, Tiwari AP, Nyayanit N, Modak M. 2020. In silico molecular docking analysis for repurposing therapeutics against multiple proteins from SARS-CoV-2. Eur J Pharmacol. 886:173430. doi:10.1016/j.ejphar.2020.173430.

Ferreira LG, Dos Santos RN, Oliva G, Andricopulo AD. 2015. Molecular docking and structure-based drug design strategies. Molecules. 20(7):13384-13421. doi:10.3390/molecules200713384.

Forli S, Huey R, Pique ME, Sanner MF, Goodsell DS, Olson AJ. 2016. Computational proteinligand docking and virtual drug screening with the AutoDock suite. Nat Protoc. 11(5):905-919. doi:10.1038/nprot.2016.051.

Gimeno A, Ojeda-Montes MJ, Tomás-Hernández S, Cereto-Massagué A, Beltrán-Debón R, Mulero M, Pujadas G, Garcia-Vallvé S. 2019. The light and dark sides of virtual screening: What is there to know? Int J Mol Sci. 20(6):1375. doi:10.3390/ijms20061375.

Kolb P, Irwin J. 2009. Docking Screens: Right for the Right Reasons? Curr Top Med Chem. 9(9):755-770. doi:10.2174/156802609789207091.

Lam PC, Abagyan R, Totrov M. 2018. Ligand-biased ensemble receptor docking (LigBEnD): a hybrid ligand/receptor structure-based approach. J Comput Aided Mol Des. 32(1):187-198. doi:10.1007/s10822017-0058-x.

Li L, Koh CC, Reker D, Brown JB, Wang H, Lee NK, haw Liow H, Dai H, Fan HM, Chen L, Wei DQ. 2019. Predicting protein-ligand interactions based on bowpharmacological space and Bayesian additive regression trees. Sci Rep. 9(1):7703. doi:10.1038/s41598019-43125-6.

Lin X, Li X, Lin X. 2020. A review on applications of computational methods in drug screening and design. Molecules 25(6):1375. doi:10.3390/molecules25061375.

Mandour Y, Handoussa H, Swilam N, Hanafi R, Mahran L. 2016. Structural Docking Studies of COX-II Inhibitory Activity for Metabo- 
lites Derived from Corchorus olitorius and Vitis vinifera. Int J Food Prop. 19(10):2377-2384. doi:10.1080/10942912.2015.1114492.

Meng XY, Zhang HX, Mezei M, Cui M. 2012. Molecular Docking: A Powerful Approach for Structure-Based Drug Discovery. Curr Comput Aided Drug Des. 7(2):146-157. doi:10.2174/157340911795677602.

Molinari A, Oliva A, Arismendi-Macuer M, Guzmán L, Acevedo W, Aguayo D, Vinet R, Feliciano AS. 2019. Antiproliferative benzoindazolequinones as potential cyclooxygenase-2 inhibitors. Molecules 24(12):2261. doi:10.3390/molecules24122261.

Morris GM, Ruth H, Lindstrom W, Sanner MF, Belew RK, Goodsell DS, Olson AJ. 2009. Software news and updates AutoDock4 and AutoDockTools4: Automated docking with selective receptor flexibility. J Comput Chem. 30(16):2785-2791. doi:10.1002/jcc.21256.

Oniga SD, Pacureanu L, Stoica CI, Palage MD, Crăciun A, Rusu LR, Crisan EL, Araniciu C. 2017. COX inhibition profile and molecular docking studies of some 2-(Trimethoxyphenyl)-Thiazoles. Molecules 21(9):4538. doi:10.3390/molecules22091507.

Pagadala NS, Syed K, Tuszynski J. 2017. Software for molecular docking: a review. Biophys Rev. 9(2):91102. doi:10.1007/s12551-016-0247-1.

Pantsar T, Poso A. 2018. Binding affinity via docking: Fact and fiction. Molecules. 23(8):1899. doi:10.3390/molecules23081899.

Pinzi L, Rastelli G. 2019. Molecular docking: Shifting paradigms in drug discovery. Int J Mol Sci. 20(18):4331. doi:10.3390/ijms20184331.

Pratama MRF, Nasibova TA, Pratiwi D, Kumar P, Garaev EA. 2021. Peganum harmala and its alkaloids as dopamine receptor antagonists: In silico study. Biointerface Res Appl Chem. 11(3):10301-10316. doi:10.33263/BRIAC113.1030110316.

Pratama MRF, Poerwono H, Siswodihardjo S. 2020. Molecular docking of novel 5-O-benzoylpinostrobin derivatives as SARS-CoV-2 main protease inhibitors. Pharm Sci. 26(Suppl1):S63-S77. doi:10.34172/PS.2020.57.

Ramírez D, Caballero J. 2016. Is it reliable to use common molecular docking methods for comparing the binding affinities of enantiomer pairs for their protein target? Int J Mol Sci. 17(4):525. doi:10.3390/ijms17040525.

Sadasivam K, Salgado Moran G, Mendoza-Huizar LH, Cardona Villada W, Gerli Candia L, MenesesOlmedo LM, Cuesta Hoyos S. 2020. Theoretical investigation of the molecular structure and molecular docking of etoricoxib. J Chil Chem Soc. 65(2):48044806. doi:10.4067/S0717-97072020000204804.

Salmaso V, Moro S. 2018. Bridging molecular docking to molecular dynamics in exploring ligand-protein recognition process: An overview. Front Pharmacol. 9:923. doi:10.3389/fphar.2018.00923.

Shrivastava N, Joshi J, Sehgal N, Kumar IP. 2017. Cyclooxygenase- 2 identified as a potential target for novel radiomodulator scopolamine methyl bromide: An in silico study. Inform Med Unlocked. 9:18-25. doi:10.1016/j.imu.2017.05.007.

Vieira TF, Sousa SF. 2019. Comparing AutoDock and Vina in ligand/decoy discrimination for virtual screening. Appl Sci. 9(21). doi:10.3390/app9214538.

Wang JL, Limburg D, Graneto MJ, Springer J, Hamper JRB, Liao S, Pawlitz JL, Kurumbail RG, Maziasz T, Talley JJ, Kiefer JR, Carter J. 2010. The novel benzopyran class of selective cyclooxygenase2 inhibitors. Part 2: The second clinical candidate having a shorter and favorable human halflife. Bioorg Med Chem Lett. 20(23):7159-7163. doi:10.1016/j.bmcl.2010.07.054. 